\title{
EL SENTIDO DEL POSITIVISMO JURÍDICO
}

Tom Campbell

Universidad Nacional de Australia

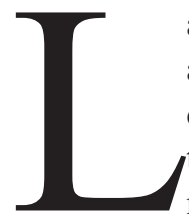

a teoría del positivismo jurídico es usualmente considerada como analítica, descriptiva y explicativa ${ }^{1}$. El sentido del positivismo jurídico, desde este punto de vista, es proporcionar una precisa caracterización del Derecho tal como éste es en realidad, en lugar de como debe ser. Esto, se supone, se sigue de la insistencia positivista en que la teoría del Derecho natural niega la distinción lógica entre descripción y prescripción y, en particular, confunde el análisis del Derecho con su crítica. Este punto de vista puede ser puesto en duda si distinguimos las prescripciones relativas al contenido del Derecho de aquellas relativas a su forma. Usando esta distinción, voy a defender que es esclarecedor y fructífero considerar el positivismo jurídico como una teoría normativa que trata de determinar qué debe ser el Derecho, no respecto de su contenido, sino respecto de su forma².

La interpretación normativa del positivismo jurídico evita las discusiones puramente semánticas sobre la definición de Derecho y sitúa los desacuerdos sobre el Derecho en un contexto significativo en el que estos análisis y descripciones en competencia son vistos como teniendo cierta conexión con ideales jurídicos alternativos, eludiendo así la doble trampa de los desacuerdos puramente definicionales sobre conceptos jurídicos, por un lado, y de los intercambios de información inconcluyentes sobre los diferentes sistemas jurídicos, de otro. Además de favorecer una mejor comprensión de las variedades del positivismo jurídico, la lectura normativa del positivismo nos legitima para desviarnos de ingratas discusiones como la de los aspectos definitorios del positivismo jurídico en sí mismo ${ }^{3}$.

\footnotetext{
${ }^{1}$ Como, por ejemplo, W.J. Waluchow, Inclusive Legal Positivism (1994), cap. 2.

${ }^{2}$ Para variaciones sobre este punto de vista respecto del positivismo jurídico ver T. Campbell, The Legal Theory of Etical Positivism, (1996); D.N. Mac.Cormick, "The Ethics of Legalism"(1989), Ratio Iuris, núm. 2, pág. 184; J. Raz, The Authority of Law: Essays on Law and Morality, (1979), pág. 50 y J. Waldron, "The Rule of Law in Contemporary Liberal Theory", (1989), Ratio Iuris, núm. 2, pág. 79.

${ }^{3}$ Pueden encontrarse útiles definiciones de trabajo de positivismo jurídico en H.L.Hart, Essays in Jurisprudence and Philosophy, (1983), págs. 57 a 59, y J. Coleman, "Negative and Positive Positivism”, (1982), Journal of Legal Studies, núm. 11, pág. 139.
} 
Para muchos teóricos del Derecho contemporáneos, el positivismo jurídico es poco más que un telón de fondo que sirve para resaltar la superioridad de sus propias caracterizaciones del Derecho, más sofisticadas y esclarecedoras. El positivismo, se pretende, describe mal el Derecho como un conjunto de reglas discretas que son identificadas, comprendidas y aplicadas mediante el conocimiento técnico de los aplicadores del Derecho, cuyo trabajo está al margen de los desacuerdos morales y políticos de la vida diaria ${ }^{4}$. Más específicamente, se dice que el positivismo jurídico no ha conseguido aceptar el giro interpretativo en la filosofía del Derecho que ha traído a la luz el papel crucial de los jueces y la cultura jurídica en la adscripción de sentido y significado a reglas que, por sí mismas, son compatibles con un número infinito de diferentes interpretaciones. La defunción del "significado literal" va de la mano con la muerte anunciada del positivismo 5 .

Puesto que cualquier caracterización del Derecho como un sistema completamente autónomo de reglas es patentemente defectuosa en tanto que ejercicio descriptivo, es fácil ver por qué se considera que el positivismo jurídico debe ser una teoría desacreditada. Todo jurista sabe que las decisiones jurídicas dependen de una multitud de factores que no vienen dados en las reglas relevantes. Las metas descriptivas del positivismo jurídico son doblemente cuestionables si se asocian con el empirismo estricto del positivismo científico, de acuerdo con el cual sólo las generalizaciones empíricas que pueden ser falsadas por observaciones sensibles son candidatas para la verdad científica ${ }^{6}$. Esto significaría que todos los juicios significativos sobre el Derecho, diferentes de las definiciones, tendrían que referirse a fenómenos observables, tales como sanciones físicas, distorsionando así la comprensión del Derecho desde el punto de vista de los participantes. Ninguna caracterización del Derecho que ignore su inteligibilidad y significado desde el punto de vista de aquellos que operan y son afectados por sus estructuras normativas puede proporcionar una caracterización satisfactoria de tal institución social compleja, como tan lúcidamente demostró H.L.A. Hart ${ }^{7}$.

Las malas descripciones del proceso jurídico que, se dice, han perpetrado los positivistas jurídicos, incluyen dogmas conceptuales no justificados que definen el Derecho en términos de hechos sociales, tales como el de

\footnotetext{
${ }^{4}$ Este es grosso modo el criticismo de los realistas jurídicos, particularmente de los escépticos ante las reglas, ver J. Frank, Law and the Modern Mind, (1930), cap. 7.

${ }^{5}$ Ver S. Kripke, Wittgenstein on Rules and Private Language, (1982); C. Yablon "The Indeterminacy of Law: Critical Legal Studies and the Problem of Legal Explanation", (1985), Cardozo Law Review, núm 6, pág. 917, y C. Norris Law, "Deconstuction and the Resistance of Theory”, (1988), Journal of Law and Society, núm. 15, pág. 165.

${ }^{6}$ Como en K.Lee, The Positivist Science of Law, (1989).

${ }^{7}$ H.L.A. Hart, The Concept of Law, (1961), cap. 2.
} 
mandatos procedentes de quien ostenta el poder, excluyendo aquellos factores morales y democráticos que se incrustan rutinariamente en la práctica real del Derecho. A esta crítica del positivismo jurídico se le da un giro ideológico al recalcar que esta sistemáticamente mala descripción del Derecho como un conjunto determinado de reglas tiene la función ideológica de camuflar el poder político de la judicatura, que está por ello mejor capacitada para imponer sus propios valores haciendo pasar sus decisiones como la aplicación moralmente neutral de reglas preexistentes y de alentar la creencia de que los ciudadanos y los jueces están, de la misma manera, limitados por un deber de manifestar total obediencia a los requerimientos de un "Derecho"objetivamente determinado. Desde este punto de vista, el sentido del positivismo jurídico se encuentra en una agenda ideológica oculta, a saber, la legitimación de un sistema que camufla el poder político de los juristas y la clase de intereses que representan ${ }^{8}$.

Este criticismo tiene una fuerza considerable y su constante repetición ha llevado a una situación en la que se sostiene ampliamente que el positivismo jurídico es una teoría jurídica obviamente falsa y quizás peligrosa, una curiosidad histórica que es inútil de cara al desarrollo del Derecho y de los sistemas jurídicos, una teoría que es expuesta sólo para preparar el terreno para otras caracterizaciones teóricas por medio de identificar los errores que ésta incorpora. Una consecuencia del eclipse del positivismo jurídico es que ya no cumple adecuadamente el papel de una teoría oficial que pueda ser utilizada para justificar la realidad e importancia del conocimiento jurídico y el papel central del Derecho de los libros en la educación jurídica. Los jueces maduros repudian abiertamente los "cuentos de hadas" asociados al positivismo jurídico, del tipo de que los jueces no crean Derecho, o de que los tribunales no tienen que adoptar decisiones jurídicas difíciles para las cuales no se encuentra guía autoritativa en los textos existentes. Hablando en términos más generales, la defunción del positivismo jurídico es bien recibida por aquellos que ven que la teoría tiene un efecto negativo sobre el desarrollo del Derecho, al oscurecer las realidades del proceso jurídico en el cual, mientras que lo realmente circunscrito a las reglas sustantivas y procesales es relativamente poco, la pretensión o ilusión de que tales reglas de hecho determinan los procesos jurídicos es un freno efectivo a la consideración abierta de argumentos relevantes y al progresivo desarrollo del Derecho. El positivismo jurídico no es sólo falso, sino que se dice también que es pernicioso como una teoría que protege intereses atrincherados y

\footnotetext{
${ }^{8}$ Ver A.C.Hutchinson y P.Monohan, The Rule of Law: Ideal or Ideology? (1986), y V.Kerruish, Jurisprudence as Ideology (1991).
} 
hace a los tribunales en nada receptivos a las necesidades de cambio social y de bienestar de los grupos oprimidos dentro de la sociedad ${ }^{9}$.

El escenario cambia sensiblemente si adoptamos el punto de vista de que el sentido del positivismo jurídico no es proporcionar primariamente instrumentos analíticos y descriptivos, sino que directamente tiene que ver con una caracterización de cómo deben ser los Derechos y los sistemas jurídicos. Si el positivismo jurídico es una teoría normativa, entonces sus inadecuaciones descriptivas no son necesariamente fatales y los prejuicios ideológicos alegados pueden ser abiertamente confrontados, valorados y contestados. Los fallos descriptivos no niegan el esfuerzo prescriptivo, a menos que los primeros demuestren la impracticabilidad de los últimos. En efecto, recalcar tales fallos, en este caso demostrando que el proceso jurídico real está habitualmente afectado por valores sociales extraños, preferencias políticas y prejuicios judiciales, resulta ser un catalizador para la reafirmación de sus aspiraciones prescriptivas. En particular, la demostración de que los tribunales están con frecuencia influidos por prejuicios de clase, género y raza, puede ser la ocasión para reafirmar el papel de las reglas al ayudar a combatir la toma de decisiones arbitraria y prejuiciosa por parte la las autoridades.

El sentido del positivismo jurídico, -entendido como una teoría ética relativa a la conducta jurídicamente relevante de los ciudadanos, legisladores y jueces- puede concebirse como la provisión de un modelo y una justificación de cara a la construcción de un sistema jurídico que se aproxime, hasta donde sea posible, a la realización de un sistema autónomo de reglas, como una parte necesaria de cualquier sistema político aceptable. La autonomía en cuestión no está ligada a los inputs de los sistemas jurídicos que, al menos en el modelo democrático del positivismo jurídico, son las reglas emanadas de las legislaturas, sino al proceso centrado en los tribunales, cuya función es aplicar reglas jurídicas a circunstancias particulares y resolver las cuestiones de Derecho y hecho que sean sometidas a su consideración ${ }^{10}$. El sentido del positivismo jurídico, así entendido, es recomendar que los sistemas jurídicos sean desarrollados de tal forma que se maximicen los beneficios sociales y políticos de tener un sistema de reglas de mandato rápidamente identificable, de tal claridad, precisión y alcance que puedan habitualmente entenderse y aplicarse sin recurrir a juicios morales y políticos controvertidos ${ }^{11}$.

\footnotetext{
${ }^{9}$ Ver R.W.Gordon "New Developments in Legal Theory" en D. Kairys ed., The Politics of Law, (1982).

${ }^{10}$ Ver G. Postema, "Law's Autonomy and Public Practical Reason”, en R.P.George, The Autonomy of Law: Essays in Legal Positivism, (1996), cap. 4.

${ }^{11}$ Así, J. Raz The Authority of Law: Essays on Law and Morality, (1979), pág. 47: "Una norma jurídica tiene una fuente si sus contenidos y existencia pueden ser determinados sin recurrir a argumentos morales".
} 
No es una tarea fácil la de rehabilitar el positivismo jurídico cuando la teoría está tan ampliamente considerada tanto intelectualmente defectuosa como retrógrada en sus implicaciones sociales y políticas. Sin embargo, el positivismo jurídico no se encuentra sin defensores e incluso entre sus críticos hay un creciente reconocimiento de que la teoría ha tenido una inmerecida mala prensa en los últimos años. En su introducción a una reciente colección de ensayos sobre el positivismo jurídico, Stephen Guest señala que mucha crítica a esta tendencia con respecto a la distinción entre Derecho y moral es superficial, y pasa por alto obvias disimilitudes entre ambos:

A causa de estas diferencias características entre reglas jurídicas y morales podemos hacer preguntas sobre el positivismo jurídico que indagan el sentido de concebir el Derecho de esta manera. Es aquí donde esto se transforma en estimulante. Si nos preguntamos la cuestión del sentido, nos movemos de un enfoque descriptivo del Derecho, en términos [digamos] del origen empírico de la autoridad jurídica, a una caracterización basada en el valor humano práctico de realizar determinadas acciones en función de las determinaciones jurídicas, en lugar de las determinaciones morales. Podemos preguntar directamente: ¿A qué sirve perpetuar la idea de que las determinaciones humanas están en cierto sentido por encima de las determinaciones morales -quizás dadas por Dios-? Tomar un camino como éste fácilmente desemboca en una orientación basada en valores, quizás en la conclusión de que el positivismo es una buena o mala teoría moral, una sub-teoría de una teoría general de la moralidad política ${ }^{12}$.

Aceptando la invitación de Guest ${ }^{13}$, este artículo reflexiona sobre el sentido del positivismo jurídico explorando algunos de los objetivos morales y políticos que subyacen y dirigen el desarrollo de la teoría. Busca ilustrar con ejemplos la creencia de que es un ejercicio esclarecedor y estimulante (por liberador) el poner en candelero los aspectos morales y políticos de la empresa positivista y, en particular, contemplar el positivismo jurídico como una teoría que recomienda que creamos y sostengamos sistemas jurídicos en los que el Derecho se identifique, se siga y aplique sin recurrir a las opiniones morales de aquellos envueltos en este proceso. Llamo a esta aproximación la teoría del Derecho del positivismo ético ${ }^{14}$.

${ }^{12}$ S.Guest ed., Positivism Today, (1996).

${ }^{13}$ Ver R. Dworkin, Taking Rights Seriously, (1077), pág. 347. Dworkin sugiere que vemos el positivismo jurídico como "una teoría política sobre el sentido o función del Derecho" en el sentido de que "el Derecho proporciona un conjunto de estándares establecidos, públicos y fiables cuya fuerza no pueda ser puesta en cuestión por algunas concepciones de los aplicadores respecto de la política y la moral”. Ver también R. Dworkin, Law's Empire (1986), págs. 45 a 113 .

${ }^{14}$ Ver T. Campbell, The Legal Theory of Ethical Positivism (1996). 


\section{Despejando el camino al positivismo ético}

Es ampliamente admitido que los positivistas jurídicos sí que tienen puntos de vista políticos y morales. Los positivistas jurídicos clásicos, Jeremy Bentham y John Austin, eran tanto utilitaristas morales como psicológicos. Incluso Hobbes, a cuya teoría del soberano absoluto pude ser remontado el positivismo jurídico, puede sostenerse que suscribió los valores fundamentales de la vida y la obediencia a Dios que van más allá del mero prudencialismo. Lo que distingue a los padres fundadores como positivistas jurídicos, es comúnmente admitido, no es la suerte de sus creencias morales, sino la separación de sus creencias con respecto a sus definiciones y descripciones de Derecho. La más famosa de todas las citas que definen el positivismo es la declaración de Austin de que "la existencia del Derecho es una cosa; su mérito o demérito otra"15.

La distinción entre la existencia y el mérito del Derecho se ha entendido que implica que la teoría del positivismo jurídico está en sí misma confinada al estudio de la existencia del Derecho como opuesta a sus méritos. Esta es una asunción falaz. La teoría acerca de cómo debe ser el Derecho puede, consistentemente con sus propias premisas, recomendar un sistema jurídico en el que se preste una atención escrupulosa a la distinción entre es y debe en relación con materias tales como la identificación y aplicación de las normas jurídicas. Ciertamente, trazar la distinción entre es y debe es una precondición de la opinión de que los aplicadores de normas deben abstenerse de hacer juicios de valor en el curso de su trabajo y de que los creadores de normas deben proporcionar normas que puedan manejarse de tal forma libre de valores. Si no se puede hacer tal distinción, entonces no tiene sentido requerir que deba ser implementada en la práctica $\mathrm{y}$, siempre que tal distinción se haga, es posible presentar razones morales para sostener prácticas no morales. Así, el sentido del positivismo jurídico puede ser, consistentemente con la distinción lógica entre ser y deber ser, un sentido moral, la presentación de una aproximación al Derecho distintiva, que identifica los beneficios sociales y políticos de un sistema de reglas que son seguidas y administradas de formas que no dependen de la evaluación moral de su contenido por aquellos que las siguen y administran.

Las múltiples relaciones entre Derecho y moral son una enmarañada red que debe ser explorada y analizada si vamos a apreciar la naturaleza del positivismo ético. Es útil distinguir las formas empíricas, conceptuales y prescriptivas de las relaciones entre Derecho y moral.

${ }^{15}$ J. Austin, The Province of Jurisprudence Determined, pág. 184. 
El positivismo jurídico está asociado a la tesis de que no hay relación necesaria (i.e. conceptual) entre Derecho y moral. Esta ha venido siendo conocida como la "tesis de la separabilidad" de acuerdo con la cual Derecho y moral pueden ser independientemente identificados y analizados en sus propios términos, sin referencias recíprocas. ${ }^{16}$ En palabras de Hart "no hay una conexión necesaria entre Derecho y moral o el Derecho como es y como debe ser" ${ }^{\prime 17}$. Desde un punto de vista más preciso y fuerte sobre las relaciones conceptuales entre Derecho y moral, llamado "positivismo duro" o excluyente", se sostiene que es conceptualmente incoherente para un sistema jurídico incorporar cualquier referencia a la moral en su regla de reconocimiento, esto es, en la lista de fuentes del Derecho que son reconocidas por los tribunales. ${ }^{18} \mathrm{El}$ positivismo duro está a menudo articulado sólo para establecer la superioridad analítica del "positivismo blando" o "incluyente". La tesis de que una regla de reconocimiento puede incluir criterios morales, pero no necesita hacerlo. En contraste, la tesis de que el Derecho debe incorporar una referencia a la moral en la regla de reconocimiento es rechazada, como una forma de teoría del Derecho natural que cae completamente fuera del alcance de las teorías positivistas.

El positivismo ético presupone el positivismo blando, sosteniendo que un sistema jurídico, con propiedad conceptual, puede incorporar o no la moral dentro de su regla de reconocimiento, pero esta pretensión es secundaria con respecto a su opinión fundamental de que un sistema jurídico no debe incluir criterios morales en la lista autoritativa de las fuentes del Derecho. Esta es una forma prescriptiva, no analítica ni descriptiva, de positivismo jurídico duro o excluyente ${ }^{19}$.

El análisis conceptual del Derecho y la moral no debe confundirse con afirmaciones empíricas sobre las relaciones fácticas implicadas entre el fenómeno moral y el jurídico. La tesis conceptual de la separabilidad no es una "tesis de la separación" como podemos llamar al punto de vista de que

${ }^{16}$ J.Coleman, "Negative and Positive Positivism" (1982), Journal of Legal Studies, núm. 11, pág. 139.

${ }^{17}$ H.L.A.Hart, "Positivism and the Separation of Law and Morals", (1958), Harvard Law Review, núm. 71, págs. 593 a 601. Ver también The Concept of Law, pág. 253.

${ }^{18}$ Para posiciones de este estilo ver J. Raz, The Authority of Law (1979), pág. 50 y R. Dworkin, Taking Rights Seriously, 2a ed., (1978), págs. 347 a 348.

${ }^{19} \mathrm{Al}$ ser capaz de seleccionar su lectura preferente de la tesis de la separabilidad de acuerdo con sus objetivos teóricos, el positivismo ético no está afectado por un "adiós al positivismo jurídico" que indica el hecho de que hay múltiples formulaciones posibles de la tesis de la separabilidad. Ver K.Fuber, "Farewell to Legal Positivism" (1996), cap. 5. Una de las muchas versiones de la tesis de la separabilidad enunciada por Fuber encaja con el positivismo ético: "la Tesis del Contenido Neutral (TCN)" de que "el contenido de la definición de expresiones jurídicas básicas debe estar libre de valores”, pág. 134. 
moral y Derecho son fenómenos empíricos distintos. De hecho, ningún positivista niega que moral y Derecho interactúen, y que hay una superposición contingente entre el contenido y las funciones de la moral de una sociedad y su Derecho. Ciertamente, la tesis de la separabilidad es una requerida presuposición de aserciones sobre la interacción entre los dos sistemas y los límites de su separación real . Además, como hemos visto, desde el punto de vista del positivismo blando, adoptado por muchos positivistas, se concibe explícitamente que los sistemas jurídicos puedan incorporar contenidos morales de una manera formal. No forma parte del positivismo ético el hacer afirmaciones empíricas sobre la separación real entre el Derecho y la moral con respecto, bien a los contenidos del Derecho ordinario y la regla de reconocimiento, o bien a las funciones sociales del Derecho y la moral, más allá de que es factible en la práctica alcanzar un grado de separación entre la moral y las actividades jurídicas de aquellos encargados de la implementación de las reglas jurídicas.

Ciertamente, el positivismo jurídico ha estado profundamente comprometido en demostrar las similitudes entre Derecho y moral como subsistemas sociales, tanto en el contenido como en la forma. La caracterización de Austin de la moral positiva, el análisis de Hart de la obligación jurídica como un subconjunto de obligaciones sociales, afirman las significativas conexiones empíricas entre Derecho y moral como fenómenos sociales. ${ }^{20}$ Ambos teóricos, sin embargo, ulteriormente describen los mecanismos por los que la moral positiva y el Derecho positivo pueden ser distinguidos y separados cuando es necesario hacerlo así.

Se ha generado alguna confusión respecto de estas cuestiones empíricas, debido al fallo en distinguir entre los métodos y los objetivos de la teoría positivista. Muchos positivistas jurídicos realmente se consideran comprometidos con un estudio científico del Derecho (y ciertamente de la moral) $\mathrm{y}$, además, valorativamente neutro, pero su positivismo metodológico no requiere que las conclusiones que alcancen estén limitadas a que la moral no está involucrada en la identificación del Derecho por aquellos realmente involucrados en los sistemas en cuestión o incluso que no hay una conexión necesaria entre Derecho y moral. ${ }^{21}$ Esto podría ser confundir el método científico de la observación de personas con la conducta científica (o no científica) de las personas observadas. Los positivistas, como científicos, pueden descubrir que los juristas no son otra cosa sino científicos en su

${ }^{20}$ H.L.A.Hart, Law, Liberty and Morality, (1963), pág. 20, y The Concept of Law, (1961), págs. 79 a 88 .

${ }^{21}$ Ver. S.R. Perry, "The Varieties of Legal Positivism” (1996), Canadian Journal of Law and Jurisprudence, núm IX, pág. 361. 
aproximación al Derecho. Sin embargo, hay que advertir que algunos positivistas han hecho tal asunción ellos mismos y han imputado su propio positivismo científico a los aplicadores del Derecho del sistema en cuestión. El positivismo ético no comete este error. Ciertamente, la queja del positivismo ético es precisamente que muchos participantes jurídicos no adoptan de hecho la actitud valorativamente neutral hacia el Derecho que sería apropiado para ellos adoptar.

Esto nos conduce al tercer modelo de relación entre el Derecho y la moral, el modelo prescriptivo, desde cuyo punto de vista podemos identificar el positivismo ético como una teoría que va más allá de la tesis de la separabilidad para mantener la pretensión de que no sólo puede sino que debe haber una clara separación entre el Derecho y la moral en la práctica del Derecho. La pretensión no es la de que no debe haber superposición entre el contenido del Derecho y el de la moral en la práctica del Derecho, una cuestión en la que la teoría, dado su alcance restringido, es básicamente neutral, sino más bien que la regla de reconocimiento no debe contener términos que inviten al juicio moral. Esta es la tesis de la separación prescriptiva o, más específicamente, el positivismo prescriptivo duro. ${ }^{22}$

Es importante destacar que excluir términos morales de la regla de reconocimiento no significa que no se pueda hacer ninguna referencia en absoluto a las creencias morales de todos o ciertos miembros de la sociedad en cuestión, o a las doctrinas morales de un libro sagrado u otra fuente de autoridad moral, habida cuenta de que estos pueden ser identificados de una forma empírica. Es posible en principio descubrir sin suscribir los puntos de vista morales prevalentes en una sociedad o contenidos en un texto particular cuyo significado pueda ser establecido mediante el uso de convenciones lingüísticas aceptadas. Lo que debe ser excluido de una regla de reconocimiento, de acuerdo con el positivismo ético, es el lenguaje que requiere que se haga un juicio moral antes de que la regla en cuestión pueda proporcionar suficiente contenido para guiar nuestra conducta concreta. Las referencias a la moral positiva o a las fuentes religiosas pueden no obstante estar incorporadas en una regla de reconocimiento, siempre que aquellas puedan ser identificadas como fuentes sociales. Tales posibles fuentes del Derecho es improbable que sirvan a los propósitos del Derecho si los crite-

${ }^{22} \mathrm{El}$ "positivismo prescriptivo duro" se presenta como relativo específicamente al positivismo ético de la regla de reconocimiento como distinto de la actividad de creación del Derecho. "Separación prescriptiva" es una etiqueta que puede aplicarse mejor a la tesis contraria al imperio de la razón dominante (disastablishmentarianism) de Neil MacCormick en el cual se afirma que el Derecho debe incorporar lo menos posible de la moral social. Ver N. MacCormick, "A Moralistic case for Amoralistic Law?", (1985), Valparaiso University Law Review, núm. 20. 
rios de identificación son tales que no proporcionan una guía con respecto al contenido del Derecho resultante de éstas. La referencia a estándares aceptados, particularmente en situaciones en las que no existen tales estándares acordados, no contribuirá a un buen Derecho, pero no hay objeción en principio a que una regla de conocimiento haga referencia a la moral social, siempre y cuando haya un conjunto homogéneo de costumbres morales en la sociedad en cuestión, y el contenido de esa moral pueda ser establecido de una forma empírica e incontrovertible.

Como estas condiciones no se encuentran en las sociedades pluralistas contemporáneas, las reglas de reconocimiento efectivas en tales sociedades deben proporcionar formas de determinar qué elementos, si hay alguno, de la moral positiva son reconocidos como jurídicamente vinculantes. A este respecto la separación prescriptiva entre el Derecho y la moral es particularmente significativa en las diversas pluralidades de las sociedades postmodernas.

Una cosa es especificar la naturaleza del positivismo ético como un positivismo prescriptivo duro, pero ¿qué nos debe llevar a aceptar la tesis de que los criterios morales no deben constar en las fuentes del Derecho utilizadas por los ciudadanos como súbditos, los burocracias como administradoras y los tribunales como aplicadores? El positivismo ético no es una tesis conceptual con respecto al significado de "Derecho", aunque puede afirmarse que encaja bastante bien con los diferentes sentidos de discurso jurídico y moral a los que se refiere Guest. Tampoco es una tesis empírica con respecto a la separación concreta entre Derecho y moral en el proceso jurídico. El positivismo ético es más una crítica que una caracterización de lo que los tribunales hacen o no hacen, hasta el punto de que el positivismo ético es incentivado en lugar de depreciado por la evidencia de prejuicios políticos sistemáticos en los tribunales. Este además requiere de justificación en términos morales y políticos. Antes de explorar estas justificaciones del positivismo jurídico como teoría prescriptiva es útil reparar en algunos obstáculos preliminares a esta lectura del positivismo jurídico.

Un obstáculo a ser superado en la presentación del positivismo ético es la asociación del positivismo jurídico con el positivismo lógico, la doctrina filosófica generalizada desde 1930 a 1950, que permitía sólo dos clases de aserciones con significado, aserciones empíricas o falsables, por un lado, y juicios analíticos sobre el significado de las palabras, por otro. ${ }^{23} \mathrm{De}$ la teoría se sigue que el lenguaje moral está excluido de la esfera del discurso significativo y que su aparente objetividad debe ser explicada en términos,

\footnotetext{
${ }^{23}$ La formulación clásica está en A.J.Ayer, Language, Truth and Logic, (1936).
} 
por ejemplo, argumentan, de que no son más que expresiones de emoción camufladas. Si el positivismo jurídico es construido como una aplicación del positivismo lógico, entonces es difícil considerarlo primariamente como una teoría ética y es fácil ver porqué es considerado como una forma de reductivismo empírico que, llevando la moral fuera del Derecho, rescata al Derecho de la esfera del mero subjetivismo.

Algunos teóricos que pueden, quizás controvertidamente, ser identificados como positivistas jurídicos, realmente expusieron los principios del positivismo jurídico y procuraron proporcionar un análisis del Derecho que prescindiera completamente de categorías morales, sobre la base de que los juicios morales no son otra cosa más que expresiones de emoción. Alf Ross y los realistas jurídicos escandinavos encajan fácilmente, por lo general, en esta categoría. ${ }^{24}$ Sin embargo, las teorías subjetivistas de la moral nunca han tenido un carácter definitorio del positivismo jurídico. Sólo necesitamos pensar en la teoría moral firmemente objetivista de Jeremy Bentham y de John Austin, cuya teoría ética utilitarista sustenta todos sus otros trabajos, para percatarnos de que no hay ninguna incongruencia general en atribuir un profundo propósito moral a las teorías positivistas. Tampoco podemos asumir que todos aquellos que adoptan teorías subjetivistas de la ética toman por ello a la moral menos en serio.

Sin embargo, es correcto decir que muchos positivistas jurídicos son conscientes de la diversidad de opiniones morales y de la naturaleza intratable de los desacuerdos morales. Los que es a menudo dado como una razón para adoptar una perspectiva positivista acerca de la separación entre el Derecho y la moral con respecto a su contenido, de manera que el Derecho pueda ser utilizado para promover la cohesión social y servir como base para la resolución de disputas entre personas con puntos de vista morales contrarios. Sin embargo, no hay ninguna base para la asociación del emotivismo en la ética, ni con la diversidad moral extrema, ni con el desacuerdo moral incorregible. La existencia de verdades objetivas no garantiza el acuerdo en cuanto a lo que éstas verdades deban ser y el desacuerdo entre aquellos cuyas convicciones están apoyadas por la creencia en la corrección objetiva de sus puntos de vista puede resultar incluso menos tratable que las disputas de los emotivistas..$^{25}$

Podríamos concluir que el positivismo jurídico ni presupone ni requiere el punto de vista del positivismo lógico sobre la moral, pero puede haber una asociación mucho más próxima con el segundo pilar del positivismo

\footnotetext{
${ }^{24}$ A.Ross, On Law and Justice, (1958).

${ }^{25}$ El mejor tratamiento general de estas cuestiones está en J.L.Mackie, Ethics: Inventing Right and Wrong, (1977).
} 
lógico, el empirismo científico, de acuerdo con el cual la experiencia es la única fuente de conocimiento, más allá de los significados de las palabras que usamos para describirlo. La asociación con el positivismo científico es un obstáculo mucho más inaccesible de superar en la representación del positivismo jurídico como una teoría ética. Los positivistas clásicos, Bentham y Austin, están fuertemente en influidos por la epistemología empirista que sustenta sus esfuerzos para liberar al Derecho del lenguaje vago e insubstancial que, en su opinión, impregna al common law. Es plausible contemplar el esquema completo de definiciones de Austin que se ocupa de mandatos, sanciones, soberanos y hábitos, como un intento de analizar el Derecho puramente en términos de categorías empíricas observables. Incluso Hart, que evita el empirismo crudo en aras a una aproximación más hermenéutica al Derecho, que se centra en el sentido del fenómeno para los participantes, se ve a sí mismo comprometido en una empresa sociológica que es emprendida para proporcionarnos una caracterización descriptiva fácilmente inteligible de un aparentemente misterioso aspecto de la sociedad humana. ${ }^{26}$

Por supuesto, hay contraejemplos de positivistas jurídicos canónicos que no son de ninguna manera empiristas científicos. Hobbes pretendía fundamentos geométricos en lugar de empíricos. Kelsen tiene una metodología kantiana independiente para separar el Derecho del empirismo científico, ${ }^{27} \mathrm{y}$ el propio Kant, a quien también se le puede considerar un positivista jurídico, no es evidentemente empirista. ${ }^{28}$ No obstante, hay lazos estrechos entre el positivismo jurídico y la rama empirista del positivismo lógico, hasta el punto de que, al distinguir el Derecho y la moral, abren el camino para la afirmación de que el Derecho debería ser de tal manera que propiciarse su explicación mediante métodos empíricos. Ciertamente, es claro que hay un fuerte sentido antimetafísico en gran parte del positivismo jurídico.

Sin embargo, el positivismo ético no es imperialista en su lectura del positivismo jurídico. Las concretas teorías positivistas tienen una gran cantidad de objetivos diferentes. No se sostiene que todos los positivismos tengan el mismo sentido, o que cualquier positivismo tenga sólo un único objetivo. Los positivistas están más o menos comprometidos individualmente con el análisis, con la descripción y con la prescripción en diferentes combinaciones y con diferentes énfasis. Lo que se sostiene es que no podemos excluir la perspectiva prescriptiva del conjunto de teorías positivistas, que este aspecto del positivismo es compatible con sus otros aspectos característicos y que

${ }^{26}$ The Concept of Law, prefacio.

${ }^{27}$ H.Kelsen, The Pure Theory of Law, (1967).

${ }^{28}$ Ver J. Waldron, “Kant's Legal Positivism”, (1996), Harvard Law Review, núm. 109, pág. 1535. 
esta rama de la teoría positivista ha sido indebidamente negada y que puede ser útil enfatizarla como un mecanismo de comprensión y como una vía de acceso de la potencial relevancia de la tradición positivista en los debates actuales en el seno de la filosofía constitucional y política.

Explicar el positivismo ético como un elemento dentro de la filosofía política no es un ejercicio histórico, aunque puede ser más esclarecedor como una forma de comprensión de los trabajos de los positivistas clásicos. Ni se trata de una interpretación "lo mejor posible" que trate de proporcionar una imagen coherente y moralmente atractiva de toda una tradición. El positivismo ético es una forma viviente y en evolución del positivismo, más que un instrumento interpretativo. No está constreñido a dotar de sentido, moral o de otro tipo, a la historia del positivismo, sino que pretende enunciar una teoría contemporánea del Derecho satisfactoria. Aceptando que el Derecho es una actividad interpretativa, en el sentido amplio en el que la interpretación es una cuestión de adopción de significados que satisfacen fines específicos evaluativos, el positivismo ético no se debilita por el hecho de que muchos positivistas jurídicos tengan importantes objetivos ontológicos y científicos que no están directamente relacionados con los valores morales que también figuran en la historia del positivismo jurídico.

Otro obstáculo a la aceptación del positivismo ético es la asunción de que el positivismo jurídico no puede permitir que ninguna valoración del Derecho entre en la sustancia de la teoría sin contradecir su premisa distintiva relativa a distinción entre el Derecho y la moral e incurriendo en una forma de iusnaturalismo. ${ }^{29}$ Sin embargo, éste es más un obstáculo psicológico que filosófico, ya que, como hemos visto, una vez que hemos distinguido entre dos formas de discurso, no hay inconsistencia en entregarse a ambas formas separadamente. Sin embargo, podría argüirse que la finalidad última de trazar la distinción en el contexto del positivismo jurídico clásico era construir una disciplina separada de la jurisprudencia, o de la ciencia del Derecho, que no diera lugar a argumentos relativos al contenido o forma adecuada de Derecho. La ciencia del Derecho no se contamina con la ciencia de la legislación.

Hay dos respuestas significativas que dar a esta verdad histórica. La primera es que los juicios morales que los padres fundadores del positivismo jurídico evitaban eran juicios sobre el contenido adecuado del Derecho, y no sobre las razones para comprometerse en un estudio científico del Derecho libre de valores. Puede haber razones morales para comprometerse con

${ }^{29}$ Tales argumentos tienen lugar en D.Beyleveld y R. Brownsword, Law as a Moral Judgement, (1989), M. Detmold, The Unity of Law and Morality: A Refutation of Legal Positivism, (1984) y J.Finnis, Natural Law and Natural Rights, (1980). 
una disciplina que no es en sí misma moral. Claramente Bentham, Austin, y menos indiscutiblemente Kelsen, tenían tales fundamentos morales para embarcarse en ello y perseguir sus propósitos. Se ha reconocido que las valoraciones del positivismo ético no están primariamente dirigidas al valor intrínseco de las empresas puramente descriptivas y explicativas, pero tampoco están dirigidas al contenido adecuado del Derecho. Su propósito es demostrar que el Derecho debe consistir en reglas fijas y claras, aplicables y aplicadas sin recurso a los juicios de valor.

La segunda respuesta es que es posible ver los elementos científicos del positivismo clásico como más directamente orientados a establecer la posibilidad de un sistema jurídico libre de valores, que a demostrar su existencia real, incluso dentro de los confines de las culturas desarrolladas. Pero libre de valores aquí significa valorativamente neutral sólo en relación con el proceso de razonamiento y las decisiones requeridas a los participantes para operar en tales sistemas, en la medida en la que están relacionadas con el reconocimiento y aplicación del Derecho, y no con su creación. Al mismo tiempo está claro que los positivistas jurídicos no se han abstenido en la práctica del formular juicios de valor en relación a la forma del Derecho. Esto puede ser o no una inconsistencia por su parte, pero no necesitamos ir más allá del análisis textual y la interpretación histórica para postular la tesis de que el positivismo ético no se opone a la tradición histórica de la cual ha surgido.

Podría ser infructuoso, sin embargo, hablar de positivismo ético si la teoría llegara a ser más inteligiblemente clasificada como una forma suave del Derecho natural que defiende una conexión necesaria entre la moral y la forma del Derecho, en lugar del contenido. ${ }^{30}$ Esto salvaría al positivismo jurídico de la vacuidad moral a costa de ser atrapado por el Derecho natural, una victoria muy pírrica. La simple respuesta a esta línea de análisis es que el positivismo ético no postula que el Derecho, para ser Derecho, deba satisfacer ciertos fines morales, en su contenido o en su forma. No es el caso de que, simplemente porque el Derecho requiere justificación moral, el concepto de Derecho esté necesariamente unido a la moral. No todo lo que requiere justificación moral es en sí mismo una empresa moral. En el positivismo ético no hay una vuelta atrás respecto de la posición positivista de que hay malos Derechos que no obstante son Derechos y malos conceptos de Derecho que, no obstante, son conceptos de Derecho. Tampoco hay ninguna pretensión de que el Derecho tenga algún propósito objetivo, más allá de aquellos determinados por los seres humanos. Estamos por lo tanto

\footnotetext{
${ }^{30}$ Para versiones diferentes de este tipo de aproximación ver D. Beyleveld y $\mathrm{R}$. Brownsword, Law as Moral Judgment, (1986), M.Detmold, The Unity of Law and Morality: A Refutation of Legal Positivism, (1984), y P. Soper, A Theory of Law, (1984).
} 
muy lejos de adoptar los conceptos claves del Derecho natural, a pesar del hecho de que la propia teoría del Derecho natural tenga una gran cantidad de argumentos relativos a la utilidad y potencial moral del Derecho positivo.

Hay múltiples similitudes entre el positivismo ético y la teoría de Lon Fuller del Derecho natural procesal, ya que ambos ven el Derecho como una empresa que persigue propósitos que requieren de determinadas técnicas a las que nos referimos característicamente como el imperio de la ley. ${ }^{31}$ Si los seres humanos van a ser sometidos al gobierno de la Ley, entonces esa Ley debe consistir en reglas que sean claras, prospectivas, practicables, promulgadas y estables. El positivismo ético contribuye a ello, pero no hace objeciones. Sin embargo, el positivismo ético no sigue a Fuller en la vía de la aseveración de una conexión necesaria entre estas técnicas y el contenido moral del Derecho que satisface estas condiciones de legalidad. El positivismo ético no es, por lo tanto, ni siquiera una forma de un Derecho natural procesal si éste se entiende que incorpora una asunción de una conexión interna y necesaria entre la buena forma y la buena substancia. Y debe ser añadido, la teoría del Derecho natural no tiene un monopolio sobre el objetivismo en teoría moral. El Derecho natural representa aquellas formas de objetivismo moral que descansan en una suerte de ese razonamiento teleológico sobre la bondad de la naturaleza que son ajenas a la tradición más utilitaria de la que el positivismo ético emerge.

Explicaciones menos discutibles de la resistencia al positivismo ético provienen de su papel como una teoría del Derecho víctima propiciatoria a la que se acusa de mucha de actual desilusión con el Derecho y los juristas. Esta victimización ha fomentado caricaturas del positivismo jurídico que lo convierten en el tipo ideal de teoría villana, moralmente ciega, intelectualmente retrógrada y políticamente opresiva, caricaturas que se diluyen lentamente a la vista de contra-argumentos y ejemplos. Los aspectos concretos de estas caricaturas que requieren un análisis más pausado están relacionados concretamente con el citado amoralismo, o incluso con la inmoralidad del positivismo, al requerir obediencia absoluta a los ciudadanos y jueces con independencia de cuál sea el contenido moral de las leyes en cuestión, una posición que se compadece mal con la práctica cada vez más aceptada de llevar a juicio a aquellos que fracasan en su deber moral de desobedecer leyes injustas. ${ }^{32}$

${ }^{31}$ L.Fuller, The Morality of Law, (1969).

${ }^{32}$ Este debate en curso se sigue del intercambio entre H.L.A.Hart, "The Separation of Law and Morals", (1958), Harvard Law Review, núm. 71, pág. 597 y L.Fuller "The Separation of Morality and Law: A Reply to Professor Hart", (1958), Harvard Law Review, núm. 71, pág. 595. Ver D. Dyzenhaus, Hard Cases in Wicked Legal Systems: South African Law in the Perspective of Legal Philosophy, (1991). 
El positivismo ético, como vamos a ver, defiende una sumisión general al Derecho que no tenemos otra razón moral para obedecer diferente el hecho de que es Derecho, y sugiere que hay razones morales importantes por las que no debemos acudir a nuestras propias opiniones morales simplemente porque el Derecho esté en conflicto con éstas. El positivismo ético no puede por lo tanto estar completamente de acuerdo con la respuesta que está abierta al positivismo descriptivo, de que el positivismo jurídico, al hacernos posible distinguir entre el Derecho que es y el Derecho que debe ser, nos hace posible ser más críticos con el Derecho y, por lo tanto, seguir nuestra conciencia cuando entra en conflicto con un Derecho injusto. Mientras que el positivismo ético no está comprometido con una obediencia al Derecho absoluta e irreflexiva, destaca el hecho de que permitir actuar sobre la base de un derecho moral a desobedecer el Derecho que pensamos que es injusto, si fuera ampliamente seguido, socavaría el Derecho como un sistema que, por medio de asegurar la conformidad, promueve la cooperación, el orden y resuelve conflictos. El positivismo ético ofrece muchas razones convincentes por las que es correcto subordinar las opiniones morales personales a los deberes jurídicos, excepto en las más excepcionales circunstancias. Esta no es una posición amoral, sino un caso de razones morales de segundo orden para separarnos de nuestros juicios morales de primer orden cuando éstos van en contra del Derecho establecido en nuestra jurisdicción. Cuáles son estas razones de segundo orden es objeto de consideración en la próxima sección.

Una segunda respuesta significativa a la caricatura de víctima propiciatoria del positivismo jurídico es destacar la confusión de asumir que los positivistas éticos deban en concreto comportarse como si estuviera en un sistema perfectamente positivista, cuando de hecho tienen que operar en situaciones en las que las normas carecen de muchas de sus características primarias de buen Derecho positivo. Un juez positivista, por ejemplo, no puede y no debe hacer juicios "mecánicos" cuando se enfrenta con normas vagas y ambiguas o con situaciones para las cuales no hay norma prevista. Todos los positivistas han defendido juicios discrecionales, al menos como soluciones "lo segundo mejor", que pueden ser la mejor práctica cuando nos enfrentamos con normas formalmente malas. A menudo las reglas bastante arbitrarias de la interpretación del Derecho legislado pueden verse como mecanismos artificiales para limitar tal discreción de una forma en la que se comprometen menos los ideales, tales como la certeza y la conclusividad, en las que el positivismo jurídico descansa.

En todo caso, el reconocimiento de que el éxito del esquema positivista depende del grado en el que hay conformidad con el modelo positivista deja claro que el positivismo ético no puede ser una teoría puramente prescripti- 
va. Las prescripciones presuponen no sólo que una sociedad puede aproximarse al ideal positivista de Derecho, sino que, en un grado significativo, esta conformidad es lograda en la práctica. El positivismo ético, al defender que seguir las reglas tiene ventajas sociales, realmente presupone más que la mera distinción entre ser y deber ser, y la preferencia por un Derecho formalmente bueno frente a un Derecho formalmente malo. Muchos de los argumentos perfilados más adelante presuponen tal conformidad general al Derecho positivo, como es el requerir que se produzcan las pautas de conducta predecibles que se sostiene que son ventajosas. Si, por ejemplo, sólo hay una conformidad desigual a las reglas de circulación, es probable que suponga menos beneficio para una persona particular someterse a las mismas. Esta es la razón por la que la eficacia, en el sentido de cumplimiento general o obediencia habitual al Derecho, es a menudo requerida como una precondición de la validez jurídica en el esquema positivista de pensamiento $^{33}$. Debe haber un umbral de conformidad, que a su vez presupone un cierto umbral de virtud formal en el Derecho con respecto a su claridad y precisión, antes de que los argumentos del positivismo ético a favor del imperio de las reglas tengan cualquier apoyo real.

Ciertas razones para adoptar el imperio de la reglas presuponen más conformidad que otras. La coordinación de gran cantidad de personas en situaciones potencialmente peligrosas es más vulnerable a la inobservancia o a la no disponibilidad del Derecho que interacciones más privadas y menos peligrosas. Pero puede concederse la idea general de que, aunque no es primariamente una teoría descriptiva del Derecho, el positivismo ético de hecho presupone un grado de realismo empírico que puede observarse en algunas sociedades la mayor parte del tiempo y en todas las sociedades cierto tiempo. Esto por sí mismo puede ayudar a explicar por qué el punto de vista del positivismo como una teoría empírica está tan firmemente atrincherado. Los beneficios normativos del positivismo ético descansan en la posibilidad empírica de implementar los modelos positivistas del Derecho que se han interpretado como descripciones de los sistemas legales reales. Este es un error comprensible.

\section{Justificando el positivismo ético}

Perfilar las razones morales que el positivismo ético proporciona para avalar su punto de vista de que las funciones de creación de normas y de aplicación de normas deben mantenerse separadas, y que la última debe ser conducida de la forma más libre de valores que sea posible, es una empresa

\footnotetext{
${ }^{33}$ Ver T. Campbell, "Obligation: Societal, Political and Legal”, en P.Harris ed., Political Obligation, (1990).
} 
desalentadora. No requiere una filosofía política completa, pues el positivismo ético no está directamente concernido con la elección de un contenido jurídico específico. Ciertamente una de sus pretensiones es que es una teoría que puede acomodar un abanico muy amplio de filosofías políticas diferentes. Pero la tarea de justificar el positivismo ético sí requiere la provisión de fundamentos para tener un tipo de sistema político que tanto se manifiesta como se contiene en el uso de las reglas como el modelo dominante de gobierno.

Afortunadamente esta extensa tarea aprovecha algunos argumentos familiares y posiciones relativas al imperio de la ley, como parte de un sistema democrático, que apuntan a las muchas ventajas de utilizar reglas tanto como instrumentos de gobierno como en cuanto límite al mismo. Para apreciar la fuerza de estos argumentos debemos primero tener un análisis de la idea de regla, tal y como ésta se presenta en la controversia acerca de que las reglas son ingredientes esenciales del gobierno legítimo, y alcanzar algo de luz sobre el papel de las reglas, tanto generalmente en la sociedad, como con respecto a las formas en las que los Estados gobiernan. Podemos empezar con la caracterización clásica positivista del Derecho de John Austin en términos de mandatos del soberano. Esta es en esencia una imagen del Derecho basada en reglas, puesto que los mandatos austinianos son mandatos generales, tanto con respecto a sus destinatarios, como con respecto a su contenido. ${ }^{34}$ Hart no ha tenido dificultad en separar estos mandatos generales de la imagen de del emisor de los mismos, ofreciendo su famoso análisis de las reglas en términos de regularidad social, que está basado en una actitud interna por parte de los participantes sociales que se manifiesta a sí misma por medio de fuertes respuestas críticas a las desviaciones de las pautas de conducta en cuestión. ${ }^{35}$ Es una característica de tales reglas sociales el ser imperativas, en el sentido de que se presentan como requerimientos a los cuales el individuo debe conformarse para evitar, bien las sanciones, o bien la crítica social y quizás la autocrítica.

A este análisis de las reglas sociales como regularidades de conducta, basado en actitudes internas de alabanza y culpa, debe añadirse una importante distinción entre "reglas de la experiencia", que ofrecen una guía, pero de las que hay que apartarse siempre y cuando sus recomendaciones no parezcan servir a sus presuntos fines, ${ }^{36} \mathrm{y}$ "reglas genuinas" o de mandato, que pretende la conformidad independientemente de su inmediata utilidad percibida. Las reglas de mandato, reglas que especifican las consideraciones que han

\footnotetext{
${ }^{34}$ J.Austin, The Province of Jurisprudence Determined, Lección I.

${ }^{35}$ The Concept of Law, (1961), págs. 79 a 81.

${ }^{36}$ F.Schauer, Playing by the Rules: A Philosophical Analysis, (1991), pág. 11.
} 
de tenerse en cuenta en las circunstancias específicas y excluyen cualquier otra consideración, son la clase de reglas que operan en los fundamentos del positivismo ético. ${ }^{37}$

Los fundamentos de las reglas comienzan por la asunción de que todas las reglas de mandato requieren justificación, aunque sólo en el sentido de que deben darse razones por las que debemos tomar en cuenta aquellas y sólo aquellas consideraciones especificadas en la regla cuando tomamos decisiones prácticas. Ciertamente, parece haber algo perverso en no tomar todas las consideraciones relevantes en cuenta en cada ocasión. En otras palabras, hay argumentos fuertes prima facie en contra de las reglas como una forma de irracionalismo. Las reglas de la experiencia son bastante fáciles de justificar puesto que facilitan decisiones rápidas que se esbozan sobre la experiencia acumulada derivada del ensayo y el error, pero podemos apartarnos de ellas si quienes las usamos decidimos que no son útiles en circunstancias particulares. Pero la reglas de mandato, que añaden a la privación de libertad de elección la irracionalidad de excluir razones relevantes, no son tan fácilmente justificables.

La tarea de justificar el gobierno de las reglas de mandato es particularmente acuciante debido a que no estamos tratando aquí de la justificación de reglas particulares por referencia a su contenido, sino de la justificación de tener reglas de cualquier contenido; la justificación para ello debe ser, por lo tanto, en gran parte independiente del contenido. Podría ser bastante fácil dar razones por las que debemos o no debemos adoptar y seguir esta o aquella regla particular, pero es menos fácil ver por qué debemos adoptar y conformarnos a las reglas en general y hacer esto sin realizar un enjuiciamiento independiente de su contenido. De ahí el atractivo del anarquismo en filosofía política y la plausibilidad de la ética de la situación o contextual en filosofía moral.

Sin embargo, una vez que nos embarcamos en la búsqueda de fundamentos para la reglas, nos encontramos con que es fácil proveerlos. En general, los fundamentos de las reglas pueden dividirse según que se trate de reglas cuyo objeto es el control, o de reglas cuyo objetivo es la coordinación. Las reglas de control son vistas como mecanismos para prevenir daños y asegurar la conducta beneficiosa, y están estrechamente ligadas a los mecanismos de sanción y educación. La estrategia de excluir ciertas materias de la

${ }^{37}$ Así, G. Warnock, The Object of Morality, (1971), pág. 65: "[Las reglas] excluyen de la consideración práctica los méritos particulares de los casos particulares al especificar de antemano lo que va a ser hecho cualesquiera que puedan ser las circunstancias de los casos particulares". Ver también J. Raz, The Authority of Law: Essays on Law and Morality, (1979), págs. 35 a 45 y 73 a 76 . 
elección de los individuos está justificada como la única forma efectiva de lograr el control de la conducta requerido. Si dejamos que se las arreglen solos, los individuos, bien por estupidez o por auto-interés, causarán un daño innecesario e inaceptable a ellos mismos y a otros. Idealmente tales reglas deberían dejar absolutamente claro lo que se requiere de las personas de una forma que no esté abierta a racionalizaciones de tal tipo que hagan posible a los individuos escapar de sus a menudo gravosos requerimientos. De ahí la alegada necesidad de excluir los términos morales de las reglas de control social, porque los términos morales invitan a juicios subjetivos que proporcionan cabida a las excepciones autointeresadas. ${ }^{38}$

Las reglas de coordinación pueden ser útilmente divididas en reglas facilitativas, tales como las reglas de los contratos, que hacen posible el logro de acuerdos y aseguran su cumplimiento, reglas de conveniencia que hacen posible la cooperación eficiente en áreas en sí mismas no moralmente significativas, tales como las reglas de circulación, reglas distributivas, que están destinadas a hacer posible que amplios grupos de personas logren pautas de conjunto en la distribución de beneficios y cargas, y reglas de output que están destinadas a coordinar las actividades económicas de amplios grupos para la producción de bienes materiales y otros beneficios sociales. ${ }^{39}$ Todas ellas tienen común la idea de que la acción coordinada es una forma más efectiva de lograr cualquier meta que requiera la participación de un amplio número de personas que a menudo se desconocen entre sí. En todos estos casos permitir a la gente decidirse sobre si seguir o no a las reglas o sobre si modificarlas en este u otro sentido invita a la confusión y ruptura en la coordinación de las actividades en cuestión. De forma semejante, la confusión sobre el contenido de tales reglas es tan destructiva de sus objetivos como lo es en el caso de las reglas de control.

Otros fundamentos de las reglas atraviesan estas categorías generales de fundamentos de las reglas. Así hay ventajas psicológicas de tranquilidad y autoconfianza en el orden, que son distintas de sus beneficios instrumentales para otros propósitos..$^{40} \mathrm{La}$ tranquilidad mental resulta promovida, particularmente en sociedades complejas, por medio de una amplia conformidad a reglas claras y precisas. También están en parte estrechamente relacionadas

${ }^{38}$ Así J.Raz, ibid, pág. 51, defiende que es una función del Derecho el "proveer estándares publicos determinados por medio de los cuales los miembros de la sociedad están sujetos a ser limitados de manera tal que no puedan excusar no conformidad cambiando la justificación del estandar".

${ }^{39}$ Ver G. Postema, "Coordination and Convention at the Foundations of Law", (1982), Journal of Legal Studies, núm. XI, pág. 165.

${ }^{40}$ Ver V.Aubert, "Some Social Functions of Legislation”, Acta Sociologica, núm. 10, (1966), pág. 99. 
con la existencia de las reglas consideraciones de justicia y equidad que capturan las diferencias y similitudes que son determinantes de cómo la gente realmente trata y cómo debe tratar a los demás, y en particular de cómo individuos y grupos son y deben ser tratados por el Estado. Tratar sistemáticamente igual casos iguales y desigualmente casos diferentes es inconcebible sin la rutinización de las reglas. ${ }^{41}$

Estas diversas fundamentaciones ilustran el amplio alcance de las consideraciones que los positivistas jurídicos pueden aportar para sustentar lo que puede parecer la difícil tarea de justificar tener reglas de mandato. Las fundamentaciones son totalmente independientes de un juicio con respecto a qué reglas particulares están justificadas, aunque hacen referencia al tipo de actividades al que se dirigen las reglas y la naturaleza general de los objetivos para cuyo logro pueden ser usadas las reglas. Todas las fundamentaciones se aplican a las reglas sociales en general así como a la reglas jurídicas; el ingrediente añadido que se requiere para justificar una regla jurídica es discutible, pero no disimilar de las fundamentaciones para tener reglas en general. Los factores que convierten las fundamentaciones para tener reglas en fundamentaciones para tener normas jurídicas tienen que ver principalmente con la seriedad de los propósitos a los que sirven las reglas y de hasta qué punto la conformidad general con reglas precisas y aceptadas es una precondición de su efectividad. Estas cuestiones están todas en el centro de la filosofía jurídica y política, pero no sustentan directamente los fundamentos generales para tener ciertas reglas de los tipos anteriormente perfilados.

Sin embargo, hay consideraciones particulares que salen a la palestra cuando se adoptan reglas oficialmente, no sólo respecto de su significado sino también en relación con el uso de la coerción y las sanciones para asegurar su cumplimiento. Ya hemos apuntado algunas de las razones positivas para asegurar el cumplimiento de las reglas y éstas pueden fácilmente trasladarse en consideraciones que sustenten la creación y sostenimiento de los Estados como formas por las que tal cumplimiento se logra. Por supuesto, hay otros argumentos que también apuntan al valor moral de los Estados, definidos como centros de coordinación de toma de decisiones y cooperación social que son obligatorios para todas las personas asociadas en una jurisdicción determinada. Estas justificaciones de los Estados puede que en sí mismas no hagan referencia a la reglas. Los mandatos particulares para la consecución de objetivos militares, económicos y sociales son, para todas las filosofías políticas, mecanismos evidentes para el logro de muchos

${ }^{41}$ Ver T. Campbell, Justice, (1988), capítulo 2. 
conjuntos de bienes de los Estados. Sin embargo, el poder que los Estados adquieren sobre los ciudadanos da lugar todavía a otro fundamento de las reglas que tiene que ver con las formas en las cuales tal poder es usado y controlado. Aquí nos encontramos con los argumentos familiares de que los Estados, los Estados justificados, deben regirse de acuerdo con reglas públicamente conocidas y controlar y coordinar a sus ciudadanos por medio de reglas que les garanticen una cierta predecibilidad y libertad en sus vidas. ${ }^{42}$

Es en este contexto en el que la relevancia constitucional del positivismo ético entra en juego. Así, hay una exigencia de que las reglas que los gobiernos deben obedecer tienen que ser claras y precisas, pues de otra forma no imponen limitaciones reales a los gobiernos. Está también el argumento de que el poder del Estado sobre los ciudadanos es tan grande y el peligro de una conducta arbitraria para beneficiar los intereses de los miembros de un gobierno y del aparato asociado a él tan amenazante, que sólo la exigencia de reglas de gobierno claras y precisas puede proporcionar cierta protección a los ciudadanos y proporcionar una esfera de garantía de la libertad individual..$^{43}$

Ambas consideraciones requieren una separación de poderes en la que los que hacen las leyes, cuya conducta es intencionalmente canalizada y controlada por las reglas en cuestión, no puedan por sí mismos hacer juicios sobre cómo se aplican éstas en las circunstancias particulares. Sin esta separación de funciones legislativas y aplicativas, se argumenta, no hay una defensa efectiva contra la aplicación selectiva e inconsistente de las leyes para adaptarse a los intereses de aquellos que tanto hacen como aplican las leyes. Todos estos fundamentos son parte de los argumentos familiares y básicos referidos al imperio de la ley que destacan las reglas del Derecho positivo claro y preciso como una precondición de la distinción práctica entre creación y aplicación del Derecho. Las reglas vagas y ambiguas efectivamente transfieren autoridad política a los tribunales que disfrutan de libertad para dar forma al Derecho por sí mismos de acuerdo con sus propios valores y preferencias.

A este respecto, el positivismo ético debe verse como parte de amplias filosofías políticas, algunas de las cuales incorporan una teoría del positivismo democrático que mantiene que la legitimidad política depende de tener reglas de mandato que se refieran al proceso democrático de las cuales emergen. Esta es por sí misma una extensa cuestión y constituye una amplia fuente de argumentos que sustentan la fuerza y relevancia del posi-

\footnotetext{
${ }^{42}$ Ver J.Waldron, "The Rule of Law in Contemporary Liberal Theory", (1989), Ratio Juris, núm. 2, pág. 79.

${ }^{43}$ P.Pettit, Republicanism, (1996).
} 
tivismo ético para las políticas contemporáneas. Así, puede argumentarse que focalizar las políticas electorales en la elección de reglas en lugar de simplemente en la elección de legisladores es un aspecto importante para hacer las elecciones de amplios electorados acordes con el ideal político del igual poder político. Además, debatir sobre las reglas y escogerlas puede tener un papel importante que jugar en la transformación de meras tomas de decisiones mayoritarias en la clase de toma de decisión democrática que produce una aproximación a un consenso sobre lo que constituye la justicia y el bien común.

Este exiguo perfil de la defensa del positivismo ético ilustra la batería de argumentos que pueden reunirse en favor del gobierno de la reglas positivas. ${ }^{44}$ No todos estos fundamentos apuntan exactamente en la misma dirección con respecto a la clase del gobierno de las reglas que requieren, pero todos destacan el papel central de las reglas de mandato expresadas en términos claros y precisos y aplicables sin recurrir a las opiniones morales de quienes están concernidos, incluyendo ciudadanos, administradores y jueces.

Tan poderosos por acumulación son los argumentos en favor de las reglas positivas que sólo una demostración de contra-argumentos abrumadoramente poderosos podría evitar que el positivismo ético estableciera sus credenciales como un ingrediente de cualquier filosofía política aceptable. Sólo el alcance de las reglas y las esferas en las cuales éstas deberían operar permanecen en tela de juicio. Mientras que haya tales contra-argumentos que se refieren a otras ideas políticas, particularmente a los valores de la espontaneidad y la libertad, estos pueden ser adaptados para reducir la variedad y el alcance de las reglas que adoptamos. Es el gobierno, no la totalidad de la vida social y económica, lo que el positivismo ético desea favorecer y limitar a través de reglas de gobierno.

Mucho más difíciles para el positivismo ético son aquellos argumentos que se proponen demostrar que el positivismo establece un ideal irrelevante porque ninguna sociedad real se aproxima ni de lejos al nivel de ejecución concreta que se requiere para lograr sus objetivos. Algunos de estos argumentos son del tipo empírico que subrayan la brecha entre los ideales de un buen Derecho positivo y la realidad de la implementación desigual, la desviación de las reglas, la ignorancia del Derecho, y la ausencia de normas. Otros argumentos son más epistemológicos y apriorísticos, al pretender demostrar que las reglas, debido a su necesaria indeterminación, no pueden posiblemente cumplir las funciones asignadas a las mismas, incluso cuando los

\footnotetext{
${ }^{44}$ Para un tratamiento mas extenso ver T.Campbell, The Legal Theory of Ethical Positivism.
} 
jueces, contrafácticamente, siempre estuvieran comprometidos a interpretar y hacer cumplir las reglas de una forma valorativamente neutral. ${ }^{45}$

Tanto los contraataques empíricos como los epistemológicos representan los mayores retos del positivismo ético. En cierto nivel pueden ser rebatidos de una manera sumariamente sencilla. Dada la general efectividad de gran parte de la administración basada en legislación específica y la utilidad general de, por ejemplo, las reglas del tráfico, es difícil para los críticos del positivismo ético demostrar conclusivamente la total impracticabilidad del modelo positivista. Por lo tanto, se transforma en una cuestión del grado en el que es factible aproximarse a este ideal y de las áreas de la vida social en las cuales la conformidad es más fácilmente alcanzable y es más importante.

De forma semejante, ningún argumento filosófico puede convincentemente negar, sin incurrir en una autocontradicción, que realmente tiene lugar un considerable grado de comunicación exitosa, particularmente entre personas que comparten el mismo lenguaje y experiencia social. Si una teoría filosófica del lenguaje no puede dar cuenta de los casos de éxito comunicativo evidente, entonces es claramente defectuosa como teoría. El problema comunicativo del Derecho radica en mantener una comunicación exitosa donde algunos participantes en el proceso tienen intereses personales en socavar tal comunicación para evitar consecuencias indeseadas.

Mucho más fructíferos en este contexto son los estudios que pretenden identificar las condiciones para la conformidad a la reglas y en particular las condiciones de la comunicación exitosa de normas dentro de comunidades lingüísticas. Una vez que se acepta que positivismo jurídico es un ideal al que se aspira, más que un depósito de verdades descriptivas y explicativas sobre todos los sistemas jurídicos, las cuestiones de la conformidad y de la comunicación pueden verse como ofreciendo una evidencia de las brechas entre la aspiración y la realidad a la que puede responderse por medio de esfuerzos para reducir esas brechas, particularmente donde están conduciendo a la injusticia y la ineficacia. Así, la evidencia de prejuicios sistemáticos en la interpretación y aplicación de reglas en relación con la clase o el género puede ser tratada mediante esfuerzos para proveer reglas que sean más explícitas con respecto a tales consecuencias indeseadas y proporcionando educación e información a los concernidos que les haga más conscientes del insidioso impacto de los prejuicios de clase y de género, y así implementar la cualidad de la aplicación imparcial de la reglas.

\footnotetext{
${ }^{45}$ Para tratamientos recientes de estas cuestiones ver B.Bix, Law, Language and Legal Determinacy (1993), y A.Marmor ed., Interpretation and Legal Theory (1992).
} 
Argumentos más abstractos sobre la indeterminación de todas las reglas, sobre la base, por ejemplo, de que cualquier secuencia de números puede potencialmente ser desarrollada en un infinito número de formas, pueden responderse con la evidencia del impacto de las expectativas compartidas en la producción de estabilidad en las prácticas y los dispositivos institucionales que pueden ser puestos en práctica para corregir desviaciones inesperadas de las pautas familiares. En general, puede aceptarse que estudios lingüísticos que demuestran la naturaleza convencional del lenguaje y la relatividad de la posibilidad de entender símbolos de culturas y periodos particulares, ponen de manifiesto que los significados compartidos y la comunicación exitosa son logros culturales inestables que requieren constante renovación y reparación. En otras palabras, el significado literal y "natural" es un fenómeno socialmente dependiente cuyos movedizos parámetros son un constante reto no sólo para el legislador y los jueces sino para todos los miembros de la comunidad lingüística que pretenden compartir un marco común para sus diferentes formas de vida.

Este gran programa de extenso éxito comunicativo parecerá ingenuo aquellos cuya familiaridad con el proceso jurídico real les lleve a suponer que los juristas y jueces están frecuentemente comprometidos con esfuerzos para desestabilizar significados acordados y discutir pautas de interpretación que facilitan la comunicación, por medio de la introducción de ambigüedades insospechadas y nuevas lecturas que favorecen sus intereses y sus puntos de vista sobre cómo el Derecho debe ser oportunamente desarrollado. Además, dada la palpable (aunque exagerada) verdad de la tesis realista de que el Derecho es aquello que los tribunales declaran por medio de sus decisiones particulares, las posibilidades de alcanzar el modelo positivista dentro de un sistema de common law adverso y que supone que los tribunales están comprometidos en el desarrollo jurídico, son ciertamente escasas.

Es indudablemente el caso de que una cultura jurídica favorable, a la que se adhieren de buena fé los aplicadores del Derecho, es una de las precondiciones para la realización del modelo positivista. Sólo los tribunales, comprometidos con ideales positivistas, y provistos con reglas que tienen niveles satisfactorios de claridad, precisión y comprehensibilidad, pueden lograr un sistema positivista de Derecho. Todos están de acuerdo en que las reglas no se administran a sí mismas, y sólo tienen significado en términos de convenciones lingüísticas de grupos específicos. Ningún individuo puede ser forzado a adoptar aquellos significados que están clarísimamente dentro de los términos de las convenciones lingüísticas de su comunidad. El realismo jurídico tiene razón al afirmar que, mas allá de un sistema finito de apelaciones, no hay forma de hacer cumplir la legalidad positivista, pero esto no supone afirmar que un sistema, que es administrado por personas que 
conversan con las convenciones comunicativas de la comunidad relevante, la cual está provista de buenas normas positivistas y comprometidas con el ideal del positivismo jurídico, no pueda conseguir lo que los tribunales reales a menudo no logran. La "ética" del positivismo ético no se refiere simplemente a argumentos justificativos en favor de la creación de normas positivisticamente buenas, sino también a la conducta y el método de aquellos que están implicados en la administración de tal sistema. Sin tribunales comprometidos con los ideales del positivismo ético, los beneficios del Derecho positivista no se pueden lograr. En la teoría del positivismo ético, la ética de los juristas debe tener mucho más que ver con el acuerdo de buena fe con el Derecho positivista que con las cuestiones más familiares de la honestidad, lealtad, diligencia y confidencialidad. ${ }^{46}$

\section{Las implicaciones del positivismo ético}

Si el sentido del positivismo jurídico es presentar la forma ideal de un sistema jurídico, es de esperar que sea parcial con respecto a reformas jurídicas que descansen en el estilo y proceso del Derecho, mientras que permanezca neutral con respecto al contenido deseable de normas particulares. El positivismo ético ayuda, además, a dotar de sentido al hecho de que caracterizaciones del Derecho supuestamente puramente positivistas científicas sean expuestas por teóricos con evidentes programa reformistas. De nadie puede predicarse esto tanto como de Jeremy Bentham, cuya hostilidad respecto de las oscuridades y mistificaciones del common law, sarcástica repudiación de las pretensiones de derechos universales e inalienables no jurídicos, y entusiasmo por la radical codificación del Derecho, son tan bien conocidas como su compromiso con la reforma social utilitaria y política. Concluyo, además, con algunas indicaciones sobre la clase de prescripciones que se siguen de la adopción del modelo positivista en las circunstancias contemporáneas. Algunas de esas indicaciones se refieren, como en el caso de Bentham, a cuestiones que en general se relacionan con el imperio de la ley, y otras, también siguiendo a Bentham, tienen más directamente que ver con el imperio de la ley dentro de un sistema democrático.

Las implicaciones del positivismo ético van más allá de la conducta de los tribunales. Ciertamente, es una teoría que se dirige primariamente a la naturaleza y forma de la legislación como la fuente preferente de Derecho nuevo. Si las normas no son claras, precisas e inteligibles, en términos de las prácticas lingüísticas de la comunidad a la cuál va dirigida, entonces

\footnotetext{
${ }^{46}$ Para un punto de vista radicalmente diferente, que implicaba al positivismo jurídico en la desbandada de la actual ética profesional jurídica, ver W.Simon, The Practice of Justice: A Theory of Lawyers'Ethics (1998).
} 
los tribunales pueden hacer relativamente poco a favor de la realización del ideal positivista.

La preferencia del positivismo ético por el Derecho legislado como primera fuente de Derecho nuevo descansa en muchos sentidos en consideraciones de legitimidad democrática, pero hay más fundamentos generales para lograr la misma preferencia que puede observarse en el énfasis dado a la prioridad de las palabras de los textos del Derecho legislado frente al menor significado dado a las palabras reales de los juicios de common law. A pesar de todas las dificultades con que tropieza la interpretación de textos, éstos ofrecen al menos la posibilidad de acuerdo acerca de lo que Derecho requiere. Con este objeto, el positivismo ético se limita a centrarse en la capacidad del sistema jurídico para identificar el texto autoritativo del Derecho y a desarrollar un modo de interpretación del texto que justifique el significado dado al mismo en el proceso de legislación. Los tribunales, desde el punto de vista positivista, deben mostrar respeto por las palabras que han sido debatidas y votadas de acuerdo con los procedimientos formales de legislación, sin tener que embarcarse en el ingrato proceso de pretender descubrir las ocultas intenciones y motivos legislativos que subyacen bajo las elecciones que hace el Derecho. Contribuir a esta idea impone al positivismo ético un deber de enunciar una teoría normativa de la legislación que identifique los momentos de creación autoritativa de legislación a la luz del ideal positivista de Derecho formalmente "bueno". Esta es una tarea que requiere en igual medida atención que el debate jurisprudencial, centrado en los tribunales, sobre la interpretación del Derecho.

Una combinación similar de consideraciones democráticas y más generales referidas al imperio de la ley figura en las implicaciones del positivismo ético con respecto a las declaraciones de derechos. Centrándonos nuevamente en los fundamentos no democráticos a favor del gobierno de las reglas, la desconfianza del positivismo ético respecto de las declaraciones de derechos se refiere principalmente a los significados vagos e indeterminados de interminablemente amplias declaraciones de derechos y cláusulas, finalmente abiertas a excepciones, que desplazan todo el peso de la responsabilidad legislativa a "las interpretaciones"de los tribunales. Mientras que esto puede ser manejable en relación con ciertos derechos humanos básicos que es generalmente aceptado que los gobiernos deben respetar pero realmente no siempre lo hacen, el alcance de los derechos fundamentales hoy incluye algunas de las disputas políticas más polémicas y características intratables de las sociedades modernas. Los ejemplos del aborto en relación con el derecho a la vida, los gastos electorales en relación con la libertad de expresión y el derecho a la huelga en relación con la libertad de asociación, sirven para mostrar que el discurso contemporáneo de los derechos humanos no se 
limita a vigilar el cumplimiento de los gobiernos en relación con conductas autoevidentemente ilegítimas. La pretensión de que se dote de precisión a estos derechos por referencia a los precedentes de los tribunales de derechos humanos sólo ilustra el hecho de que la precisión se logra de una forma $a d$ hoc por aquellos mismos cuerpos cuyo papel es aplicar y hacer cumplir los derechos en cuestión. ${ }^{47}$

El positivismo jurídico, en su forma normativa, no excluye por sí mismo que se dote de prioridad lexicográfica a normas fundamentales en caso de conflicto con otras fuentes del Derecho y es generalmente neutral con respecto a los argumentos basados en la democracia a favor y en contra de atrincherar normas, pero la teoría produce un espectro de consideraciones contrarias a dotar de tal estatus a aserciones de derechos inespecíficas y carentes de límites que generan controversias tan pronto como se realizan intentos de concretarlos de una forma que afecte a las circunstancias del caso. ${ }^{48}$ Paradójicamente, es la ausencia de mecanismos para trasladar tales abstracciones en decisiones determinativas - algo de lo que los positivistas están rutinariamente acusados de pretender que están en posesión- lo que lleva a los positivistas jurídicos a tal inquietud sobre derechos jurídicos indeterminados. La confianza jurídica en métodos kantianos de universalización, o en técnicas rawlsianas de toma decisión imparcial, o en la exhortación dworkiniana a interpretar una tradición jurídica como "la mejor posible", contribuye escasamente a tranquilizar al positivismo ético respecto de que no hay necesidad de mucha más precisión en la declaración de derechos, antes de que sean dejados en manos de la incierta jurisprudencia de los tribunales, cuyas determinaciones son jurídicamente soberanas en el caso de declaraciones de derechos constitucionalmente atrincheradas.

Estos ejemplos de las implicaciones prácticas del positivismo ético pueden ser ampliados en relación con materias tales como la resolución alternativa de disputas, las leyes anti-discriminación y el control jurídico de la acción de la administración. Sin embargo, los ejemplos dados son suficientes para ilustrar la forma en la que considerar el positivismo jurídico como un ideal político genera un debate focalizado en torno a lo que son cuestiones

\footnotetext{
${ }^{47}$ Para una visión general crítica de estas cuestiones, ver T.Campbell, "Democracy, Human Rights and Positive Law", (1994), Sydney Law Review, núm. 16, pág. 195.

${ }^{48}$ W.J.Waluchow, en Inclusive Legal Positivism, cap. 5 defiende que el positivismo jurídico excluyente no puede explicar el Derecho de los Estados dotados de "carta de derechos" donde el significado moral forma parte del Derecho. El positivismo jurídico duro prescriptivo acepta sus consideraciones pero toma su demostración como un fundamento para rechazar "cartas de derechos" que inviten a lecturas morales. R.Dworkin, Freedom's Law:The moral reading of the American Constitution, (1996), defiende que tales lecturas morales de la Constitución americana, aunque generalmente no aceptadas explícitamente, son normales y deben ser elogiadas.
} 
de las más discutibles y significativas planteadas en el Derecho constitucional contemporáneo. Estos debates muestran que el positivismo ético tiene algo que ofrecer que es muy diferente de las abstracciones generalizadas que pretenden capturar los aspectos generales de todos los sistemas de Derecho reales y las definiciones de conceptos jurídicos fundamentales que son a menudo utilizadas para circunscribir el debate imaginativo sobre la reforma de los sistemas jurídicos.

Los liberadores y precisos debates que han sido puestos en escena al interpretar el positivismo jurídico, junto con otras importantes teorías jurídicas, como ideales políticos en competencia, no se limitan a específicas materias políticas y constitucionales, sino que también afectan a alguno de los debates abstractos más persistentes en la teoría del Derecho como es el de la naturaleza de la obligación jurídica. Por ejemplo, si añadimos al análisis de las reglas de mandato anteriormente ofrecido, razones del tipo al que nos hemos referido a la hora de proveer fundamentos para el gobierno de las reglas, entonces probablemente estaremos llegando tan cerca como es posible a una noción plenamente significativa de obligación jurídica, $y$ una que es bastante diferente de los fundamentos racionales relacionados con las sanciones que puedan seguirse con indiferencia hacia el Derecho, con lo que el positivismo jurídico está normalmente asociado. Al ofrecernos una multiplicidad de razones por las que debemos conformarnos a las normas, con relativa abstracción de nuestra aprobación o desaprobación de su contenido, el positivismo ético vuelve más inteligible la idea de que hay una obligación de obedecer el Derecho que no es contingente respecto de nuestra aprobación de su contenido específico. Esta, no obstante, esa otra historia y un propósito diferente.

(Trad. de Ángeles Ródenas) 
$\triangle \quad$ DOXA 25 (2002) 